\title{
EXPERIMENTAL ESTIMATION OF WEAR RESISTANCE OF POLYAMIDE COMPOSITES, REINFORCED BY CARBON AND GLASS FIBRES USED IN METAL-POLYMER GEARINGS
}

\author{
Myron CHERNETS, ${ }^{*}$ Myroslav KINDRACHUK, ${ }^{*}$ Anatolii KORNIENKO*, Alina YURCHUK ${ }^{* *}$
}

\author{
*Aerospace Faculty, Department of engineering, standardization and certification, \\ National Aviation University, 1, Liubomyra Huzara ave., Kyiv, Ukraine, 03058 \\ "Aerospace Faculty, Department of computerized electrotechnical systems and technologies, \\ National Aviation University, 1, Liubomyra Huzara ave., Kyiv, Ukraine, 03058 \\ myron.czerniec@gmail.com, nau12@ukr.net, anatoliy_k@ukr.net, pruner@ukr.net
}

received 18 May 2020, revised 3 March 2021, accepted 5 March 2021

\begin{abstract}
The method of model triboexperimental studies to determine the basic mathematical model parameters of materials wear resistance at sliding friction is considered. The quantitative relative experimental characteristics of wear resistance of glass fibre and carbon fibre reinforced polyamide used in metal-polymer gear couple have been determined. Wear resistance functions of these functional polymeric composites have been established as the basic ones in the tribokinetic mathematical model of material wear for sliding friction conditions. Also, according to the conducted researches, wear resistance diagrams were constructed. They may be used as graphical indicators of wear resistance in the required range of specific friction forces. The dependences that connect the characteristic functions of wear resistance of these materials (obtained by the developed mathematical tribokinetic wear model) with linear wear and gearing service life are presented.
\end{abstract}

Keywords: Method for determining the characteristics and functions of wear resistance, reinforced polyamide, dispersed glass and carbon fibres, metal-polymer gears

\section{INTRODUCTION}

New developments in industrial technologies require constant improvements of materials used (Kindrachuk et al, 2018). New hardfacing and advanced materials are always introduced, and many of them will find their application much later (Pashechko et al., 2018, Gorokh et al., 2018). A very important task here is the prediction of wear loss, or service life of mechanisms and machines, but most scientists predict durability of materials only. Various methods and power schemes of triboexperimental studies to evaluate the wear resistance of materials are used. Here, it is possible to determine the absolute and relative characteristics of the studied tribocouple's materials under the given conditions. They can be used to make a comparative assessment of materials' wear resistance under identical test conditions. The most common of these include linear, mass and volume wear loss (absolute characteristics) and the intensity and rate of wear (relative characteristics). It is more convenient to use relative wear characteristics. These quantitative characteristics of materials' wear resistance are traditionally determined under specified normal loading in tribocouple. However, the calculation methods for estimating wear using them are not adequate as far as they are, as a rule, calculated for one value of specific load. Therefore, it is necessary to perform numerical triboexperimental studies of tribocouples in a sufficiently wide range of specific loads, the results of which should establish the characteristics of wear resistance. These characteristics will become the basic ones in mathematical models of wear kinetics of sliding (or rolling with slippage) tribocouples. Polymeric materials have some peculiarities if they operate in couple with steels, and we should take this into account (Kindrachuk et al., 2019 a, b,).

This paper presents the results of the studies on the method of model triboexperiments (Chernets and Lenik, 1997, Chernets, 2019) with sliding friction to establish the wear resistance characteristics of reinforced polyamide composites paired with steel used in metal-polymer gear couple.

\section{STATE OF THE ART}

As it is known, during the operation of gears under the influence of friction forces acting on the gear in the torque transmission, tooth wear occurs inevitably. The wear rate is the practical criterion that determines the gears' lifespan (Zarkoa et al., 2019, Greco et al., 2011). However, despite the obvious necessity at the design stage of carrying out the predicted calculation of gears' durability according to the criterion of acceptable linear wear of the teeth, effective and reliable methods of calculation have not yet been developed. There are several methods of calculation of this kind in the literature. In the 1970s and 1980s, Drozdov Yu.N. has been working on this problem in USSR. (Drozdov, 1969, 1975, Drozdov and Nazhestkin, 1990, Pronikov, 1978, Grib, 1982). There is no continuation of these studies by other investigators in the countries of the former USSR. Since the late 1990s, several scientists have been developing such methods to calculate certain types of gears. Among them, there are: Bajpai et al., (2004), Brauer and Andersson, (2003), Flodin, (2000), Flodin and 
Andersson (1997, 1999, 2000, 2001), Kahraman et al., (2005), Kolivand and Kahraman (2010), Mao (2007), Pasta and Mariotti (2007), Wu and Cheng (1993). Archard's law of abrasive wear is used in all simplified calculation methods to evaluate wear of teeth. According to him, the wear rate is linearly dependent on the friction path and contact pressure. In closed gearings operated with lubrication, abrasive wear does not occur and the use of these methods is therefore unreasonable. Besides, other factors are not covered by these methods, which will be discussed below. This fact makes it impossible to use them in engineering practice. Even in open gear drives, abrasive wear is also uncommon, because in the presence of an abrasive medium, gears quickly lose their performance.

The estimation of service life of gearings is a very important task. Reasons of gearings failure may vary a lot. Basically, teeth may fail due to fatigue or sudden rupture (Gębura et al., 2019), surface fatigue (Brandao et al., 2014), fretting-fatigue (Wei et al., 2020), contact-fatigue (Liu et al., 2020) or may be worn out (Brethee et al.). In problem of lifespan estimation, scientists focus their attention to particular reasons of failure. Brandao et al. (2014) did a study of pitting and fatigue influence on gears wear. They developed a numerical model that involves simulation of micropitting and fatigue wear. But, these two processes were modelled separately and combined later. DIN $20 \mathrm{MnCr} 5$ steel was used as gear material. Bravo et al. (2015) were solving the task of gear couple deterioration until the final failure. They point out the complexity of this task. Both gears were manufactured of plastic materials. Authors succeeded a lot in developing effective means to extend the time for plastic gear applicability.

Hegadekatte et al. (2010) studied the wear in miniature gear mechanisms made of ceramics or cemented carbides. The Archard's wear model was selected as the most appropriate. Simulation was done using FEM method. This time, the lifespan prediction by this method for macrogears is questionable. To determine wear coefficient, they used experimental pin-on-disk and twin-disc wear data. Wang et al. (2019) made a numerical model and simulations of wear process of heavy loaded helical gears based on the modified Archard's wear model for elastohydrodynamic lubrication. They also found relations between load factors, gear geometric parameters and wear rate of tooth contact surface. These data, unfortunately, were not checked experimentally.

The surface condition and gear modification also influence simulation; besides, the roughness effect during simulations is also an important factor. Bodach et al. (2012) studied the numerical simulation of positively modified gears' roughness influence on lubrication and wear process. Results showed that tooth geometry change influences much more than change in roughness during operation. Guilbault and Lalonde (2019) made a significant effort to predict tooth roughness change with high accuracy $(1.27 \mu \mathrm{m}$ predicted compared to $1.3 \mu \mathrm{m}$ measured). They proved that micropitting failure starts on the surface, while pitting crack initiates at some depth under the surface. But, both these studies cannot spot the method to predict lifespan of the gear.

Raadnui (2019) studied the wear and other deterioration processes of gears, including contamination and corrosion influence on gears conditions. He deduced the relationships between operating conditions, wear debris size, morphology and failure mode. This work's results can't be used directly to predict the lifespan of gear trains, but may be used for quantitative prediction of wear loss. For wear tests, he used a test set with two industrially produced gears engaged.
The dynamic wear prediction model established by Liu et al., (2016) has a task to connect surface wear process and gear dynamics. At low rpm, the effect of initial tooth wear is negligible, but as rpm rises, the wear effect becomes more significant. But, the question about experimental studies still requires a solution. Feng et al. (2019) updated the dynamic model by taking into account vibrations occurring during operation, and vibration-wear bias. Tooth wear was monitored continuously and corrected tooth shape (as a result of wear) continuously being added to the model. All the results were checked by laboratory gear test rig. This model may predict the wear of gears with acceptable accuracy.

\section{WEAR TEST PROCEDURE}

When conducting model triboexperimental studies, they usually use plane friction contact. In this case, the conditions of wear are unchanged throughout the experiment. A pin-on-disc tribometer is a very good solution for that.

To study the polymer composite-steel couple's wear, a friction PoD layout was used (composite pin - AISI 1045 steel disk).

In the current work, tribological tests were conducted using a pin-on-disk test layout (composite pin - steel disk), which ensures that the conditions of friction and wear are constant during the experiment. The following research program was used: contact pressure $P=1,2,5,10,20 \mathrm{MPa}$, sliding speed $v=0.4 \mathrm{~m} / \mathrm{sec}$, wear path $=2000 \mathrm{~m}$, diameter of pin $\mathrm{d}=2 \mathrm{~mm}$. Friction factor measured for materials was 0.3 .

For wear test, we used Anton Paar tribometer TRB ${ }^{3}$ (Fig. 1).

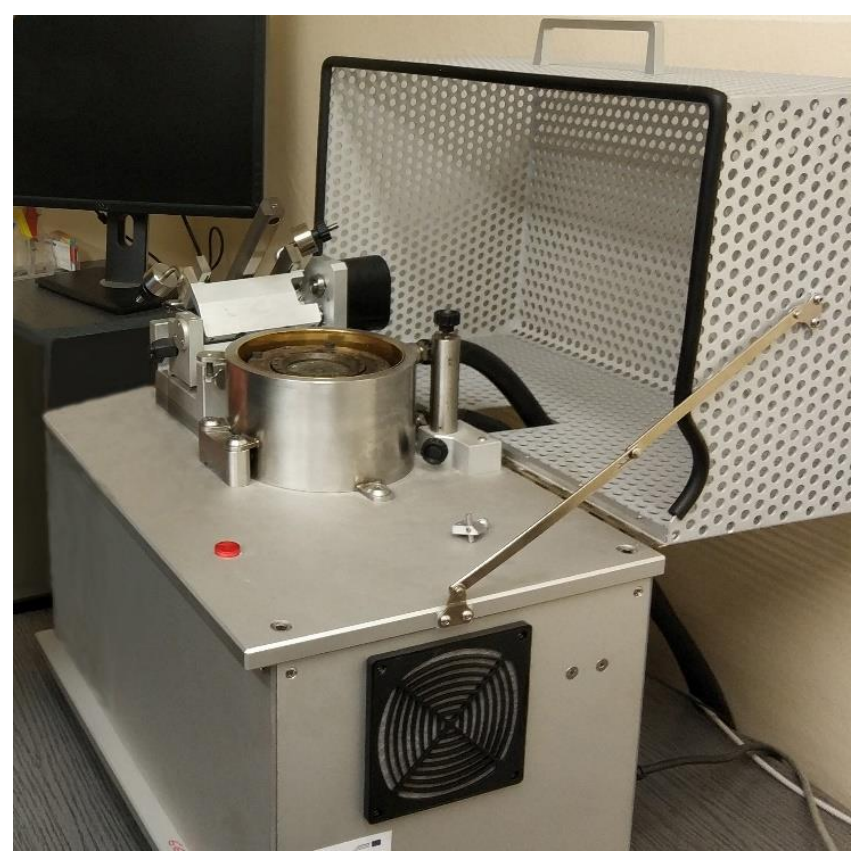

Fig. 1. High temperature Anton Paar tribometer TRB ${ }^{3}$

This tribometer allows to have $60 \mathrm{~N}$ deadweight load, and combined with standard specimen, $20 \mathrm{MPa}$ contact pressure may never be achieved. But, to meet the requirements of the test, a modified pin specimen was manufactured (Fig. 2). The contact area of the modified specimen with cone section is $3 \mathrm{~mm}^{2}$, which gives $20 \mathrm{MPa}$ at $60 \mathrm{~N}$ load. Reduced pin diameter section length is about $2 \mathrm{~mm}$, and no plain contact distortion was observed. Mass 
wear loss was measured by electronic balances with accuracy $0.001 \mathrm{~g}$ Axis model ANG $200 \mathrm{C}$.

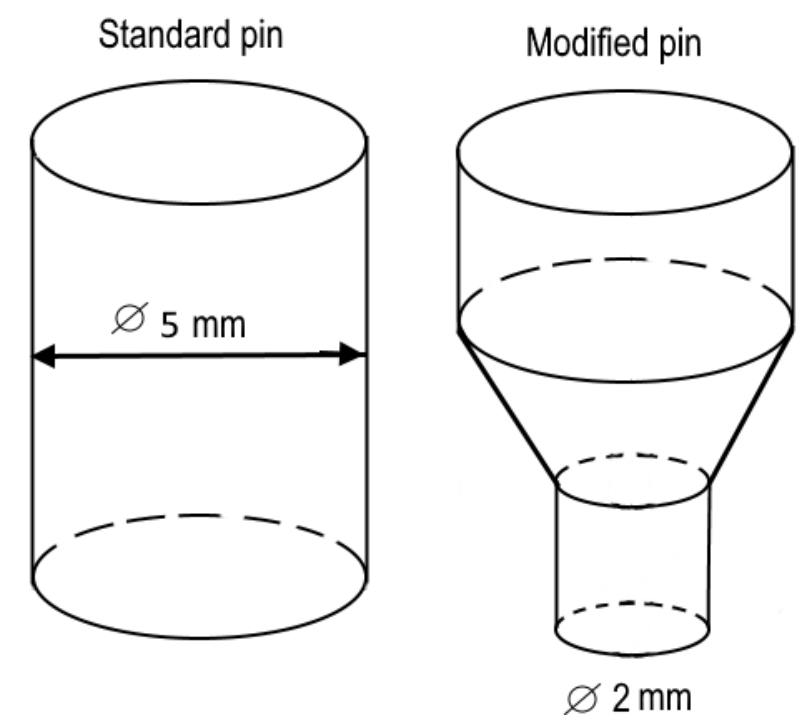

Fig. 2. Standard and modified pin for $\mathrm{TRB}^{3}$ tribometer

\section{RESULTS AND DISCUSSION}

After the wear test, mass wear loss $\Delta M$ of specimens was determined, and their average linear wear $h$ was calculated by the formula:

$h=\frac{\Delta M}{\rho S}$

where $\rho$ is the density of polyamide composite with 30 wt. \% of fibre reinforcement; $s$ is the nominal contact area.

The next stage of data processing of triboexperimental studies was the establishment of experimental wear resistance model characteristics, in particular wear resistance functions $\Phi_{i}$ at certain levels of specific friction forces $\tau_{i}$ in friction contact

$\Phi_{i}=L_{i} / h_{i}$,

where $L_{i}=v t$ is friction path, $v$ - friction velocity, $t$ is the duration of the experiment, $h_{i}$ - linear wear of samples, $\tau_{i}$ is the discrete value of specific friction force at contact pressure $i$. We should note that the friction forces can be significantly different with the same contact pressure in the tribomechanical system. They depend on the sliding friction coefficient, which can be in a wide range (from 0.005 to 0.01 for mixed friction, from 0.05 to 0.1 for boundary friction, from 0.1 to 1.0 for dry friction) (Kurdi et al., 2018, Bongaerts et al., 2018, Wand and Wang, 2013). The specific friction force, the value of which determines the wear rate of tribosystem elements, in tribotechnology is calculated by Amonton - Coulomb formula:

$\tau=f P$,

where $f$ is friction coefficient; $P$ is nominal contact pressure.

The final stage of processing experimental data is to determine the basic characteristics of wear resistance for a mathematical model of the study of materials wear kinetics at sliding friction (Chernets and Lenik, 1997, Chernets et al., 2011). Using the established by (2) discrete experimental characteristics of wear resistance - wear resistance functions. Their approximation is performed according to the following relation (Chernets, 2019a, Chernets et al., 2011):

$\Phi_{k}(\tau)=\mathrm{C}_{k}\left(\frac{\tau_{s k}}{\tau}\right)^{\mathrm{m}_{k}}$,

where $C_{k}, m_{k}$ - are nonlinear and exponential wear resistance characteristics of tribocouple materials, which are determined by formula (4) through approximation by the method of least squares through several iterations based on the experimental values of wear resistance functions $\Phi_{i}$ determined earlier by formula (2), $\tau_{S}$ - shear strength of materials, $k=1 ; 2$ - designation of tribocouple elements. The characteristic function of wear resistance is the basic integral parameter of the developed mathematical wear model (Chernets and Lenik, 1997, Chernets et al., 2011, Chernets, 2019b).

The above procedure was used to determine the wear resistance characteristics $\mathrm{C}_{k}, \mathrm{~m}_{k}$ of polyamide composites with a filler volume fraction of $30 \%$ coupled with steel (calculated by formula (4)):

carbon fibre reinforced polyamide PA6 + 30CF (UPA 6130 UV): $=C_{C F}=3.1 \cdot 10^{5}, m_{C F}=2.3, \tau_{S C F}=48 \mathrm{MPa}$; glassfibre reinforced polyamide PA6 + 30GF (PA6-L-CB30-1): $=C_{G F}=$ $1.26 \cdot 10^{5}, m_{G F}=1.9, \tau_{S G F}=52 \mathrm{MPa}$.

On Fig. 3, points show the experimental discrete values of the calculated wear resistance functions $\Phi_{i}=\Phi_{i}\left(\tau_{i}\right)$ of both the composites, and the lines show their wear resistance diagrams $\Phi(\tau) \sim \tau$ as indicators of their wear resistance in the studied range of friction forces.

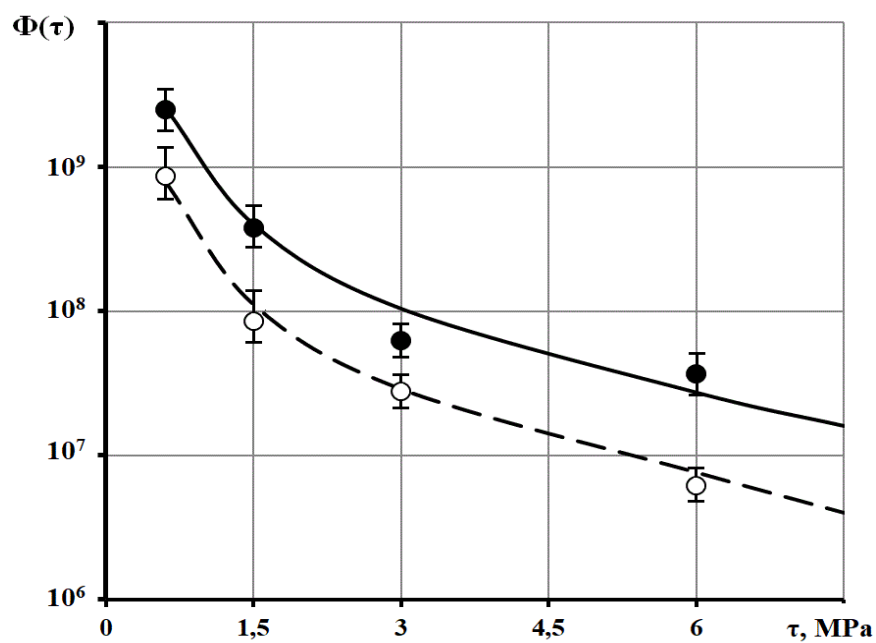

Fig. 3. Diagram of wear resistance of polyamide composites: solid line - carbon fibre reinforced composite, dashed line - fiberglass reinforced composite; dark circles - experimental values of wear resistance function for carbon fibre composite, light circles - for fi -breglass reinforced composite. Each point is an average value of 3 wear tests

The above mentioned material's wear resistance diagram (WRD) allows to visually evaluate the material's wear resistance over the entire range of specific friction force change. In addition, when studying the wear of several materials, it is easy to compare their wear resistance under different loading conditions.

Based on the results of triboexperimental studies and WRD of these polymeric composites, the comparative wear resistance was evaluated, and we found that carbon fibre-reinforced composite 
would be $C_{C F} / C_{G F}=2.46$ times more wear resistant than fibreglass reinforced composite.

Wear resistance is inverse to wear intensity. Therefore, respectively, experimental inverse function of linear wear resistance will be the experimental function of the intensity of linear wear $\mathrm{I}_{\mathrm{hi}}\left(\tau_{\mathrm{i}}\right)$ for corresponding values of specific friction force $\tau_{\mathrm{i}}$ :

$\frac{1}{\Phi_{i}\left(\tau_{\mathrm{i}}\right)}=\frac{h_{i}}{L_{i}}=I_{h i}\left(\tau_{i}\right)$,

Also, wear resistance function $\Phi_{i}\left(\tau_{\mathrm{i}}\right)$ is related to the linear wear rate $\gamma_{h i}\left(\tau_{i}\right)$ by the following formula:

$\Phi_{i}\left(\tau_{\mathrm{i}}\right)=v / \gamma_{h i}\left(\tau_{i}\right)$,

and inverse:

$\gamma_{h i}\left(\tau_{i}\right)=v / \Phi_{i}\left(\tau_{i}\right)=v I_{h i}\left(\tau_{i}\right)$,

So, these experimental evaluation results of materials' wear resistance may be compared with the results of other authors obtained under similar wear conditions, first of all, at the same range of specific friction force and sliding speeds.

Basic wear characteristics may be used to calculate the total linear wear of tribomechanical sliding system if wear characteristics of one of its elements are known. This is especially important in case of dissimilar wear resistance of coupled materials and dissimilar tribocontact conditions. Total linear wear of tribosystem $h_{\Sigma}$ can be calculated as follows:

$h_{\Sigma}=h_{1}+h_{2}=h_{1}\left(1+h^{\prime}{ }_{1}\right)=h_{2}\left(1+h_{2}^{\prime}\right)$,

where $\mathrm{h}_{1}{ }_{1}, \mathrm{~h}_{2}{ }_{2}$ - relative linear wear of coupled elements (pinion 1 and gear 2).

They are calculated as $\Phi_{k}(\tau)$ taking into account (4) according to the following dependencies:

$h^{\prime}{ }_{1}=\frac{h_{2}}{h_{1}}=\frac{\Phi_{1}(\tau)}{\Phi_{2}(\tau)}=\frac{C_{1} \tau_{S 1}^{m_{1}} \tau^{m_{2}}}{C_{2} \tau_{S 2}^{m_{2}} \tau^{m_{1}}} K_{t}^{(2)}$,

$h^{\prime}{ }_{2}=\frac{h_{1}}{h_{2}}=\frac{\Phi_{2}(\tau)}{\Phi_{1}(\tau)}=\frac{C_{2} \tau_{S 2}^{m_{2}} \tau^{m_{1}}}{C_{1} \tau_{S 1}^{m_{1}} \tau^{m_{2}}} K_{t}^{(1)}$,

where $K_{t}^{(1)}, K_{t}^{(2)}$ - coefficients of elements mutual overlapping at tribological contact.

Correspondingly, in a gearing:

$h_{\Sigma}=h_{k}\left(K_{t}^{(k)}+h^{\prime}{ }_{k}\right)$;

$h_{\Sigma}=h_{1}\left(-K_{t}^{(1)}+h^{\prime}{ }_{1}\right)$;

$h_{\Sigma}=h_{2}\left(K_{t}^{(2)}-h_{2}^{\prime}\right)$;

$K_{t}^{(1)}=1$,

$K_{t}^{(2)}=z_{1} / z_{2}$

where $Z_{1}, Z_{2}$ are respectively the number of teeth of pinion and gear.

Linear wear $h_{k}$ of gears teeth are interrelated, so:

$h_{1}=\frac{h_{2} h_{2}^{\prime}}{K_{t}^{(2)}} ; \quad h_{2}=\frac{h_{1} h_{1}^{\prime}}{K_{t}^{(1)}}$,

Taking into account (2):

$v T_{1}=\Phi_{1} h_{1} ; v T_{2}=\Phi_{2} h_{2}$,

where $T_{1}$ and $T_{2}$ - are the durabilities of the studied tribocouples. Accordingly, relative durabilities $T_{1}^{\prime}$ and $T_{2}^{\prime}$ of tribomechanical system elements will be determined as:
$T^{\prime}{ }_{1}=\frac{T_{2}}{T_{1}}=\frac{\Phi_{2}(\tau) h_{2} K_{t}^{(2)}}{\Phi_{1}(\tau) h_{1} K_{t}^{(1)}}=\frac{\Phi_{2}^{2}(\tau)}{K_{t}^{(1)} \Phi_{1}^{2}(\tau)}$

$T^{\prime}{ }_{2}=\frac{T_{1}}{T_{2}}=\frac{\Phi_{1}(\tau) h_{1} K_{t}^{(1)}}{\Phi_{2}(\tau) h_{2} K_{t}^{(2)}}=\frac{\Phi_{1}^{2}(\tau)}{K_{t}^{(2)} \Phi_{2}^{2}(\tau)}$

Then,

$T_{1}=\frac{T_{2} \Phi_{1}^{2}(\tau)}{\Phi_{2}^{2}(\tau) K_{t}^{(2)}}=T_{2} T^{\prime}{ }_{2}$

$T_{2}=\frac{T_{1} \Phi_{2}^{2}(\tau)}{\Phi_{1}^{2}(\tau) K_{t}^{(1)}}=T_{1} T_{1}^{\prime}$

\section{CONCLUSIONS}

The method of triboexperimental studies of materials at sliding friction according to pin-on-disk friction layout provides the correct determination of relative wear resistance characteristics $\Phi_{i}$ of materials due to the invariance of tribocontact conditions throughout the experiment. The developed method's efficiency is confirmed by an example of the tests given here of the two types of polyamide-based composite materials $\mathrm{PA}+30 \% \mathrm{CF}$ and PA6+30\%GF under the studied range of specific friction forces.

Obtained experimental values of $\Phi_{i}$ were used to construct wear resistance diagrams of the studied materials. They graphically display their wear resistance (Fig. 3).

These wear resistance diagrams of materials, as graphical indicators of their wear resistance, allow to determine the comparative wear resistance of the studied composites for any required value of specific friction force.

Determined as a result of approximation of experimental wear resistance indicator values (functions $\Phi_{i}$ ) and material's wear resistance characteristics $C_{k}, m_{k}$ are required for the assessment of wear and durability of metal-polymer gears by the developed method of gears calculation (Chernets et al, 2011, Chernets, 2019, Chernets and Chernets, 2017) or by the corresponding numerical methods used in problems of contact mechanics (Kindrachuk and Galanov, 2014).

Using the characteristics of material's wear resistance $C_{k}, m_{k}$ in tribocouple, it is possible to determine the relative linear wear of tribosystem elements $h^{\prime}{ }_{1}, h^{\prime}{ }_{2}$, their total wear resistance $h_{\Sigma}$ and durabilities $T_{1}$ and $T_{2}$ of tribosystem elements.

This methodology allows transforming wear rates, friction force values, and friction factors, available from scientific literature, into wear resistance functions. Thus, any of the results obtained with dissimilar test methods may be used as a database for further research.

\section{REFERENCES}

1. Bajpaj P., Kahraman A., Anderson N.E. (2004), A surface wear prediction methodology for parallel-axis gear pairs, Journal of Tribology, 126, 597-605.

2. Bobach L., Beilicke R., Bartel D., Deters L. (2012), Thermal elastohydrodynamic simulation of involute spur gears incorporating mixed friction, Tribology International, 48, 191-206.

3. Bongaerts J. H. H., Day J. P. R., Marriott C.,. Pudney P. D. A, Williamson A.-M. (2018), In situ confocal Raman spectroscopy of lubricants in a soft elastohydrodynamic tribological contact, Journal of applied physics, 104, 014913.

4. Brandão J.A., Seabra J.H.O., Castro J.D., Martins R. (2014), On the simulation of simultaneous fatigue and mild wear during a micro- 
pitting gear test, International Gear Conference: 26th-28th August 2014, Lyon, P. 523-531.

5. Brauer J., Andersson S. (2003), Simulation of wear in gears with flank interference - a mixed FE and analytical approach, Wear, 254, 1216-1232.

6. Bravo A., Koffi D., Toubal L., Erchiqui F. (2015), Life and damage mode modeling applied to plastic gears, Engineering Failure Analysis, 58, 1, 113-133.

7. Brethee K, Zhenc D., Gua F., Ball A (2017), Helical gear wear monitoring: Modelling and experimental validation, Mechanism and Machine Theory, 117, 210-229.

8. Cherepova T., Dmitrieva G., Tisov O., Dukhota O., Kindrachuk M. (2018), Research on the properties of Co-Tic and Ni-TiC hip-sintered alloys, Acta mechanica et automatica, 13, 1, 57-67.

9. Chernets M. (2019a), A method for predicting contact strength and life of archimedes and involute worm gears, considering the effect of wear and teeth correction, Tribology in Industry, 41, 1, 134-141.

10. Chernets M. (2019b), Method of calculation of tribotechnical characteristics of the metal-polymer gear, reinforced with glass fiber, taking into account the correction of tooth, Eksploatacja i Niezawodnosc Maintenance and Reliability, 21, 4, 546-552.

11. Chernets M., Chernets Ju. (2017) The simulation of influence of engagement conditions and technological teeth correction on contact strength, wear and durability of cylindrical spur gear of electric locomotive, Proc. JMechE. Part J: Journal of Engineering Tribology, 231, 1, $57-62$.

12. Chernets M.V., Kelbinski J., Jarema R.Ja. (2011), Generalized method for the evaluation of cylindrical involute gears, Materials Science, 1, 45-51.

13. Chernets' M.V., Lenik K. (1997), On estimation of materials durability, Materials science, 33, 834-840.

14. Drozdov Ju. N. (1969), The calculation of gear trains wear resistance [In Russian], Mashinovedenie, 2, 84-88.

15. Drozdov Ju. N. (1975), Development of wear calculation method and friction simulation [In Russian], Wear resistance, Science, Moscow, 120-135.

16. Drozdov Ju.N., Nazhestkin B.P. (1990), The development of methods to calculate weaer of toothed wheels [In Russian], Engineering Gerald, 11, 15-17.

17. Feng K., Borghesani P., Smith W. A., Randall R.B., Peng Z. (2019), Vibration-based updating of wear prediction for spur gears, Wear, 426-427, part B, 1410-1415.

18. Flodin A. (2000) Wear of spur and helical gears. Dissertations and Theses, UMJ Dissertations Publishing.

19. Flodin A., Andersson S. (1997), Simulation of mild wear in spur gears, Wear, 207, 1-2, 16-23.

20. Flodin A., Andersson S. (1999), Wear simulation of spur gears, Lubrication science, 5(3), 225-250.

21. Flodin A., Andersson S. (2000), Simulation of mild wear in helical gears, Wear, 241(2), 123-128.

22. Flodin A., Andersson S. A (2000), Simplified model for wear prediction in helical gears, Wear, 249 (3-4), 285-292.

23. Gębura A., Kłysz S., Tokarski T. (2019), Monitoring wear of gear wheel of helicopter transmission using the FAM-C and FDM-A methods, Procedia Structural Integrity, 16, 184-191.

24. Gorokh G., M.I.Pashechko M., Borc J., Lozovenko A., Kashko I., Latos A. (2018), Matrix coatings based on anodic alumina with carbon nanostructures in the pores, Applied surface science, 433, 1 , 829-835.

25. Greco A.C., Erck R., Ajayi O., Fenske G. (2011), Effect of reinforcement morphology on high-speed sliding friction and wear of PEEK polymers, Wear, 271, 9-10, 2222-2229.

26. Grib V.V. (1982), Solwing of tribotechnical problems by numerical methods [In Russian], Science, Noscow.

27. Guilbault R., Lalonde S. (2019), A stochastic prediction of roughness evolution in dynamic contact modelling applied to gear mild wear and contact fatigue, Tribology International, 140, 105854

28. Hegadekatte V., Hilgert J., Kraft O., Huber N. (2010), Multi time scale simulations for wear prediction in micro-gears, Wear, 268, 316324

29. Kahraman A., Bajpaj P., Anderson N.E. (2005), Influence of tooth profile deviations on helical gear wear, Journal of mechanical design, $127,4,656-663$.

30. Kindrachuk M., Volchenko A,. Volchenko D, Volchenko N., Poliakov P., Tisov O., Kornienko A. (2019b) Polymeres with enhanced energy capacity modified by semiconductor materials, Functional materials, 26, 3, 629-634.

31. Kindrachuk M.V., Volchenko O.I., Volchenko D.O., Volchenko N.O., Polyakov P.A., Kornienko A.O., Yurchuk A.O. (2019a), Polymeric Materials Modified by Semiconductor Substances in Friction Units of Braking Devices, Journal on nano- and electronic physics, $11,3,03014$

32. Kindrachuk V., Galanov B. (2014), An efficient approach for numerical treatment of some inequalities in solid mechanics on examples of Kuhn-Tucker and Signorini-Fichera conditions, Journal of the Mechanics and Physics of Solids, 63, 432-450.

33. Kolivand M., Kahraman A. (2010), An ease-off based method for loaded tooth contact analysis of hypoid gears having local and global surface deviations, Journal of mechanical design, 132, 7, 071004.

34. Kurdi A, Hongjian Wang H, Chang L. (2018), Effect of nano-sized TiO2 addition on tribological behaviour of poly ether ether ketone composite, Tribology International, 117, 225-235.

35. Liu H., Liu H., Zhu C., Tang J. (2020), Study on gear contact fatigue failure competition mechanism considering tooth wear evolution, Tribology International, 147, 106277 (Journal pre-proof)

36. Liu, X., Yang, Y., Zhang, J. (2016), Investigation on coupling effects between surface wear and dynamics in a spur gear system, Tribology International, 101, 383-394.

37. Mao K. (2007), Gear tooth contact analysis and its application in the redaction of fatigue wear, Wear, 262, 11/12, 1281-1288.

38. Pashechko M., Krzysztof Dziedzic K., Mendyk E., Jerzy Jozwik J. (2018), Chemical and phase composition of the friction surfaces Fe$\mathrm{Mn}-\mathrm{C}-\mathrm{B}-\mathrm{Si}-\mathrm{Ni}-\mathrm{Cr}$ hardfacing coatings, Journal of tribology, 140(2), 021302.

39. Pasta A. , Mariotti Virzi G. (2007), Finite element method analysis of a spur gear with a corrected profile, Journal of strain analysis, 42 , 281-292.

40. Pronikov A. S. (1978), Reliability of machines [In Russian], Machine engineering, Moscow.

41. Raadnui S. (2019) Spur gear wear analysis as applied for tribological based predictive maintenance diagnostics, Wear, 268, 316-324.

42. Wang H., Zhou C., Leia Y., Liu Z. (2019), An adhesive wear model for helical gears in line-contact mixed elastohydrodynamic lubrication, Wear, 426-427, part A, 896-909.

43. Wang, Y., Wang, Q. J. (2013), Stribeck Curves. Encyclopedia of Tribology, 3365-33150

44. Wei J., Niu R., Dong Q., Zhang S. (2020), Fretting-slipping fatigue failure mode in planetary gear system, International Journal of Fatigue, 136, 105632.

45. Wu S., Cheng H.S. (1993), Sliding wear calculation in spur gears, Journal of Tribology, 115, 493-500.

46. Zorkoa D, Kulovec S, Duhovnika J, Tavcar J. (2019), Durability and design parameters of a Steel/PEEK gear pair, Mechanisms and machine theory, 140, 825-846. 